\section{Cytomegalovirus infection in an HIV patient with duodenal papillitis}
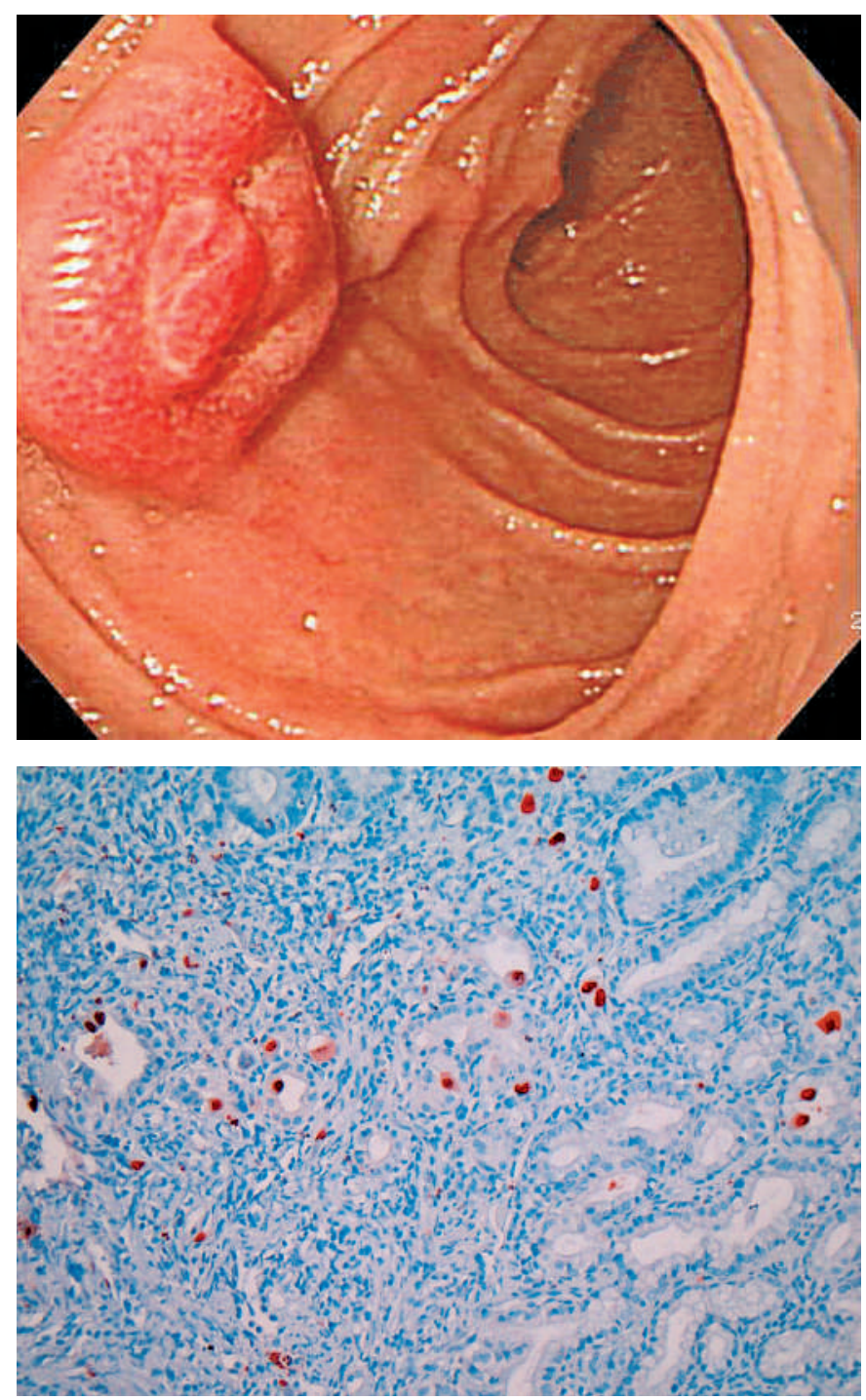

Figure 2 Immunohistochemistry staining, showing the characteristic multiple cytomegalovirus inclusion bodies (original magnification $\times 200$ )

A 52-year-old man had undergone appendectomy 2 months previously, at which time he was incidentally diagnosed with human immunodeficiency virus (HIV) infection. One month later, he revisited the hospital, complaining of vague abdominal pain with intermittent watery diarrhea. A colonoscopy was carried out, revealing multiple small ulcers in the ascending and transverse colon, biopsies from which revealed nonspecific inflammation. Two weeks later, he was hospitalized for persistent symptoms. Laboratory data demonstrated a white blood cell count of $1900 / \mathrm{mm}^{3}$ and a CD4+ lymphocyte count of $108 / \mathrm{mm}^{3}$. Chest radiography and abdominal computed tomography showed
Figure 1 Upper endoscopy, showing an of Vater with hyperemic mucosal changes in the second portion. unremarkable findings. An upper endoscopy was performed. The esophagus and stomach showed unremarkable findings, but in the duodenum there was an edematous ampulla of Vater, with hyperemic mucosal changes in the second portion (Figure 1). Histopathological examination revealed active papillitis with a few large cells infected with cytomegalovirus (CMV), confirmed by specific staining. Immunohistochemistry staining showed characteristic multiple viral inclusion bodies (Figure $\mathbf{2}$ ). organisms in patients with acquired immune deficiency syndrome (AIDS) and
CMV infection is one of the commonest frequently affects the liver and biliary tree. It is usually part of a disseminated disease. Cholestatic liver function tests have been reported in one-third of patients and radiographic evidence of sclerosing cholangitis in 3-11\% [1]. Sclerosing cholangitis, known as AIDS cholangiopathy, is associated with papillary stenosis. Endoscopic sphincterotomy is carried out in patients with papillary stenosis, with marked relief of pain in most cases [2]. In the case of the biliary tree, the viral inclusions do not always have the characteristic owl's-eye appearance, and immunohistochemistry for CMV is extremely useful in doubtful cases [3].

Endoscopy_UCTN_Code_CCL_1AB_2AZ_3AC

Y. S. Kim¹, Y. D. Cho', J. S. Lee', S. Y. Jin², C. S. Shim ${ }^{1}$

${ }^{1}$ Dept. of Internal Medicine, Soon Chun Hyang University Hospital, Seoul, South Korea

2 Dept. of Pathology, Soon Chun Hyang University Hospital, Seoul, South Korea.

\section{References}

1 Jacobson MA, Cello JP, Sande MA. Cholestasis and disseminated cytomegalovirus disease in patients with the acquired immunodeficiency syndrome. Am J Med 1987; 84: 546 549

2 Bonacini M. Hepatobiliary complications in patients with human immunodeficiency virus infection. Am J Med 1992; 92: 404 - 411 ${ }^{3}$ Goldin RD, Hunt J. Biliary tract pathology in patients with AIDS. J Clin Pathol 1993; 46: $691-693$

Corresponding author

\section{S. Shim, M.D.}

140-743, Digestive Disease Center Soon Chun Hyang University Hospital 657 Hannam-dong, Yongsan-gu · Seoul · South Korea

Fax: $\quad+82-2-709-9696$

Email: csshim@hosp.sch.ac.kr

DOI: $10.1055 / s-2006-944923$ 